\title{
A Case Study of Communication Difficulties between a Chinese Advanced Learner and Native Speakers
}

\author{
Xiaoling Jin \\ Beijing Normal University Hong Kong Baptist University United International College (UIC), Zhuhai, China
}

\begin{abstract}
The paper focuses on the communication difficulties between a Chinese advanced learner and native speakers. The research is carried out through a case study approach and is grounded on the data collected from recording conversations between a Chinese participant and two native speakers. The recorded conversations are spontaneous, covering general topics encountered in real life. Three linguistic findings are: first, grammar does not usually affect advanced learners in speaking whereas the lack of appropriate vocabulary may be a bigger challenge; second, advanced learners could learn contents words and expressions without instruction but through a rich target language input; third, incorrect pronunciation can be corrected through consistent physical practice and corrective feedback. Also, the research shows that foreign language anxiety, cultural differences and $\mathrm{L} 1$ influence play important roles in communication with native speakers. As to the study strategy, this research emphasizes the importance of continuous language exposure for advanced learners. This case study could be applied by students and teachers in EFL classrooms and will also contribute to the study of Chinese English.
\end{abstract}

Index Terms - case study, immersion environment, Chinese L2 learners, Chinese English, communication difficulties

\section{INTRODUCTION}

\section{Motivation of the study}

Molly, a Chinese student, whose English is at advanced level, is studying for an MA in TESOL at a university in the U.K. She is having a home-stay experience with a native British family. She had a great opportunity to get closer to the English language as well as British culture with this target language immersion environment. Researchers have been studying the importance of immersion-styled teaching and engagement strategies in the U.S. since the late 1960s (Kim, Hutchison \& Winsler, 2015) but little research has focused on individual learner factors relating to learners' effectiveness in language learning abroad (Kang \& Ghanem, 2016). This research will certainly contribute the understanding of immersion in the respect of individual language development abroad. During Molly's stay, she gradually noticed herself having some difficulties in communication with the native speakers and she was anxious to assimilate into the foreign community. In order to have a clearer picture of her own weakness, she determined to conduct a thorough research on her own communicative performance, aiming at discovering both linguistic difficulties and also understanding underlying psychological difficulties.

The research questions

1. What linguistic and psychological difficulties will Chinese advanced learners have when speaking with a native speaker?

2. Why do these difficulties occur in speaking between Chinese advanced learners and native speakers?

3. What study strategies can be adopted to reduce the difficulties in speaking?

This research focuses vertically on the communication difficulties Molly encountered rather than spreading horizontally across the difficulties that may confront an L2 learner. Molly, as a Chinese advanced learner, surrounded by native speakers, is going to confront her linguistic difficulties in respect of lexis, grammar and pronunciation, as well as revealed any psychological difficulties that may occur. It should also be borne in mind that the research has been unfolded in the communication between the participants so that the real life situations will have impact on the actual outcome of the data. Hopefully, this research can make contributions to the field of teaching English as a second language and enrich the understanding of Chinese English.

\section{Methodology}

\section{Participants}

Maley (2009) discovers that advanced English language learners are those who have come a long way in the language and, although having a degree of self-sufficiency, they are typically acutely aware of a margin for further improvement. Similarly, if an advanced learner is strongly motivated to reach a higher-level of English proficiency, s/he 
might persist in making the effort to aim for native-like linguistic competence, especially those whose occupation requires a professional command of English. However, with respect to communication and interaction with others in every-day life, one's original identity will appear spontaneously in the language as well as being revealed through other forms of intercourse. In the light of the efficiency of advanced learners' communication in real life, they should be proud of their linguistic achievement, whilst respecting the uniqueness of their own origins.

Sykes (2015) carried out a case study by interviewing a successful language learner to understand the study approaches this learner adopted effectively. Sykes focused on a particular participant and it has provided concrete details to show key characteristics of what a good language learner could be. Cohen, Manion, \& Morrison (2007) point out the uniqueness of case study which provides vivid examples of real people in real life which is far more interesting than listing abstract theories or principles. This research has carried out also using a case study approach, involving a Chinese advanced learner and two British native speakers. The researcher, referring to as Molly, is the Chinese advanced learner, actively participating in the study throughout. Molly is 26 years old, with a BA in business English and currently pursuing her MA in TESOL for a year in the UK. Her English language is at advanced level and she is capable of using English flexibly and effectively for social and academic purposes. Molly met Max and Pauline over Christmas, 2014 and she has had a home-stay experience with them for almost a year. During her stay, she has experienced a rich English language and cultural exposure in most aspects of family and social life from interactions with native speakers.

The native British couple, Max and Pauline, are the L1 informants and keen to contribute to the study. They are originally from Liverpool, UK, however, they do not have a scouse accent, the lack of which Molly found more intelligible. Max graduated in architecture at Liverpool College of Building in 1962. He has been working as a church and conservation architect since 1961 to the present. Max's interests include antique clocks and reading. Pauline completed her English language and English literature O levels in 1965. She was a director of a shipping agent in the UK for 42 years and her life-long interests include English history and literature.

\section{Methods and procedures}

In this research, Molly represents the Chinese advanced learner and she remains in this English immersion environment for the duration of the study. From June $23^{\text {rd }} 2015$ to June $27^{\text {th }} 2015$, some of her general conversations with Max and Pauline have been recorded as the first group of data for the research. After about four weeks, further conversations have been recorded from July $26^{\text {th }}$ to July $30^{\text {th }}$ as the second group of data. During the four weeks between recording, Molly has made efforts, such as listening to BBC radio, watching English language films on TV, conversing widely with native speakers, and writing essays, all with the object of improving her level of competence in the use of the second language. Therefore, there should be some differences between the two sets of data with the second group expecting to give some indication of improved capability.

All the conversations recorded are authentically derived from normal discourse, covering a relatively wide range of topics encountered in everyday life. All the voice data collected has been transcribed into written notes verbatim and then sampled for specific analysis. All transcriptions of this research have been completed by Molly and she endeavored to identify as many linguistic mistakes as possible in her own language performance. Then Max and Pauline, as the native speakers, reviewed the voice data and the transcripts for confirmation and double-checking for errors and difficulties. In the process of recording, Molly kept a close track of the psychological difficulties she had during the communication and wrote them down promptly for a record, and these data would support the study from another perspective other than language.

The actual linguistic difficulties in speaking during the research have been identified with evidence from the voice data and written transcripts, while the psychological difficulties were recorded by Molly according to her immediate gut feeling at that time. Obviously, the psychological data would be subjective, but it was as perceived directly by the participant herself. Molly's speaking performance has been centered throughout the study, in all aspects of grammar, lexis and pronunciation. Possible reasons for any communication difficulties were analyzed in specific detail in the subsequent discussion section and relevant study strategies have been suggested accordingly. Although there is a potential risk of compromising the study from having the researcher as a participant, Max and Pauline have been asked to verify the authenticity of all difficulties encountered in the communication. However, to improve the validity of future study, a procedure of peer examination of the data could be undertaken, perhaps involving a second L2 participant.

\section{DisCUSSION WITH RELEVANT STUDIES}

All the representative samples of the recorded conversation cove most of Molly's weakness in speaking. Molly has first read through the transcriptions, and has identified as many errors and difficulties as she could in her own language performance. Subsequently, Max and Pauline have double-checked the transcriptions to identify any further matters that they feel Molly should address. From mistakes collected from the data, it seems that Molly's biggest challenges in her communication with native speakers are lexis and grammar, as well as several pronunciation difficulties. It is worth noting that the process of finding these challenges is based on a standard accuracy of native speaker norms. However, it appears that their communication normally went smoothly and misunderstanding only occurred few times during the whole recording time. See Chart 1 below: 


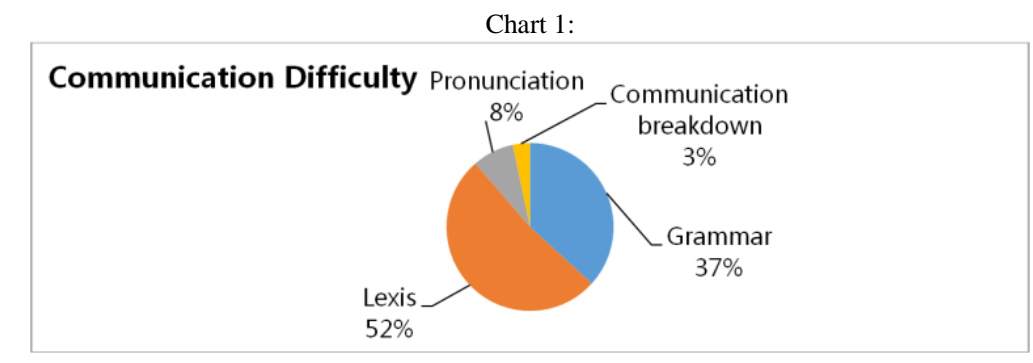

It is worth noticing that Molly could find herself almost all of the pronunciation mistakes she has made but she could only distinguish about one fifth of her lexical errors and one third of her grammatical mistakes. This process could certainly help Molly to notice the gap between herself and a native speaker; as a consequence she could be more aware of her spoken weakness. See Chart 2 below:

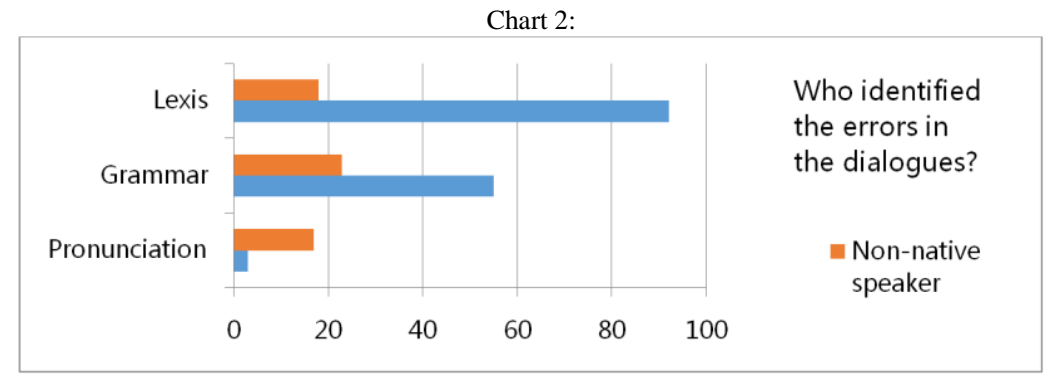

Harley (2010) says there is little room for errors in speaking. In order to ensure successful communication, speakers not only need to make themselves clear but also must respond quickly without much time to think. Despite the linguistic difficulties in speaking that this research mainly focus on, the nature of communication could not be overlooked and the features of Molly's communication strategies have been analyzed. Cook (2008, p112) pays considerable attention to communication strategies and regards them as "a natural part of conversational interaction" that people fall back on to make themselves understood. Bygate (1987) divides communication strategies into two categories: Achievement strategies and Reduction strategies. Achievement strategies contain guessing, paraphrase and cooperation with the others. Reduction strategy could also be labeled Avoidance strategy so as to avoid some tricky structures or difficulties in expressing an idea through lack of vocabulary.

It is apparent that Molly is inclined to make use of different communication strategies in her communication. When she is not sure whether it is correct to use a word, she always paraphrases it or employs an alternative word. For example, not knowing the word "commission", she said if a salesperson sells something, he can have a share. Sometimes it might contribute to her learning process if she would take the risk and use the word that first came to mind. Besides, she makes considerable use of guessing and gesture to help her communication with native speakers. It may be effective but the disadvantage is that she might be losing some good opportunities of negotiating for meaning which would otherwise facilitate her linguistic competence. Also, she frequently applies repetition in her speech, although appropriate repetition could emphasize the key point in the conversation and promote understanding. In addition to the achievement strategies in communication, Molly relies on the strategy of avoidance to keep herself out of trouble. For example, when Max wanted to talk to Molly about the differences between the Chinese and British educational systems, Molly narrowed the topic down to the differences of teaching English, with which she was more familiar.

\section{Lexical difficulties in communication}

Data presentation and analysis

With regards to lexical difficulty, Molly's biggest challenge is her application of noun, collocation and determiner. In everyday conversation, new vocabulary seems to occur only occasionally implying that Molly has a good command of English vocabulary. See details in Chart 3 below: 


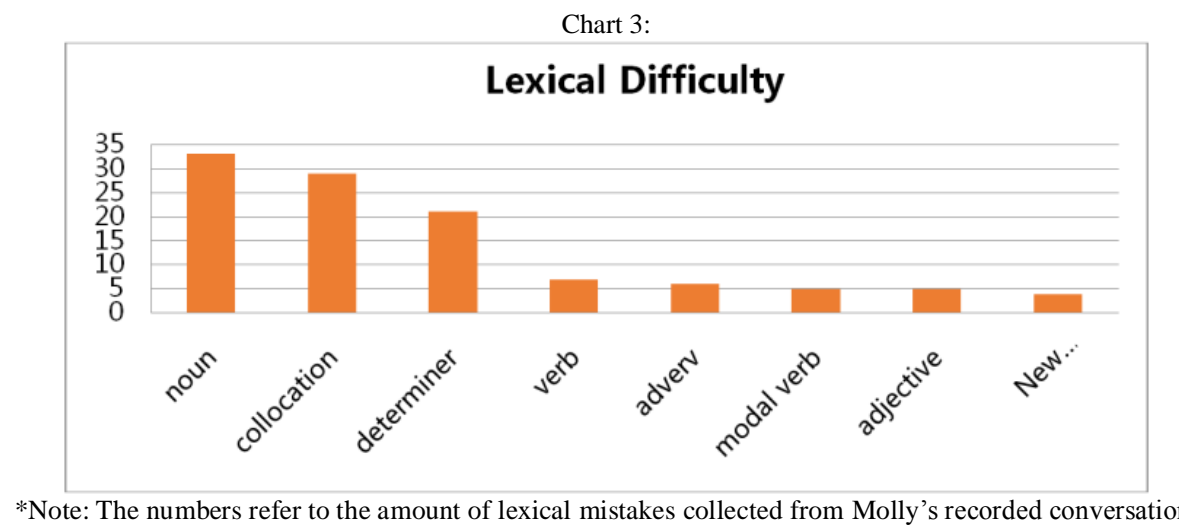

- Nouns

According to the data, Molly sometimes struggled to find the appropriate lexical noun in a certain context. For example, she wanted to tell Pauline that her friend Ny has got a full-time job in a pub, but she was hesitant to use the word "pub" and said "Ny's got this full-time job in that bar, pub." It sounded like she expected Pauline to think about it and pick up the correct noun. The same thing happened when she wanted to explain to Max about a pair of trousers, she said "but the texture, the material is very old..." She was not sure which noun she should use and was hoping that her interlocuter would understand her by adding an alternative, perhaps more accurate, word. However, finding the appropriate word is sometimes controversial because it is very much dependent on the context.

However, sometimes Molly did use an inappropriate word without offering an alternative. Take one of her conversation with Max for example:

Max: Nowadays upper classes address their servants with "please" and "thank you", but it was not always so.

Molly: Of course. I mean that is not just to respect the others, it is also a showing of your own good manners.

Molly used the noun "showing" in this context where the word "display" or "demonstration" might be better. As another example, when Molly was explaining the educational system to Pauline, she said "Actually our study plans, I think, is a bit too heavy for the students." What does she mean by "study plans"? Actually she wanted to say the Chinese curriculum is a bit too heavy for school children. As a matter of fact, she knew the word "curriculum" but she was either afraid to use it or temporarily could not bring it to mind, so that sometimes she had to invent expressions for herself.

- Determiners

Relating to nouns, Molly also has difficulties with determiners. Carter and McCarthy (2006, p335) define determiners as "the type of reference a noun phrase has", which could be definite or indefinite (the, a), possessive (my, her), and demonstrative (this, those). One third of Molly's errors with determiners are her mixing up of the indefinite determiner and demonstrative determiner. For example, she said "the night when Ny made me this roast dinner..." when she should have said "a roast dinner" and she said "or take them to those local farms" while ought to have been "some local farms", because she was not actually meaning a particular dinner or specific farms. She thought that using these demonstrative determiners could help associate her listener with the situation she was referring to and smooth the conversation by establishing such a connection.

- Collocations

Gairns \& Redman (1986) concluded that the most common types of collocation are: "subject noun + verb", "verb + object noun", "adjective + noun" and "adverb + past participle used adjectivally". It seems Molly tends to have trouble with "verb + object noun". For example, she said "She met friends here" where she actually meant "made friends", "You have to do the examination" instead of "take/sit the examination", "...parents change the ages of their child" rather than "falsify the age". Perhaps a native interlocutor could understand what Molly meant within the context, but they would soon notice the difference in how L2 learners describe things and where their weaknesses lie. As to the other three types of collocation, they do not often appear in Molly's spoken English, and it certainly leads to baldness in her spoken language. For example, she could get by with "A man walked by in the dark." but fail to use other verbs such as totter, stroll and trot. It does not mean that L2 learners have to speak using complicated collocations, but it seems that they tend to be satisfied with words like "walk and run", "happy and sad" and they perhaps do not bother at all to use adverbs to add any vivid flavour to their speech.

- Adjectives and adverbs

Concerning adjective and adverb, as mentioned above, it seems that Molly does not often make use of these two types of word in her spoken English. Her most frequently used adjective is "nice" and "good", and perhaps the only adverbs she uses are those about frequency, such as sometimes, often and never. She is capable of understanding a lot of adjectives and adverbs when she hears them in conversation but, unfortunately, she does not take the opportunity of using them herself. Perhaps she is reserved in this respect and adopting the avoidance strategy, being afraid to make a mistake.

- Verbs 
Molly is having problem with verbs and their -ing form. For example, she said "They won't be just want to stay in Wales." instead of "wanting", and she said "But people in the city, they just trying to get to high school, and then university or, maybe, college." when she should have said "try". Carter and McCarthy (2006, p423) say that "The -ing form is used with auxiliary be to form progressive aspect." Molly sometimes forgets to add an -ing to the verb or omits the auxiliary $b e$. This is almost certainly the result of L1 influence because the verb will not be modified whether it is a progressive action or not. Moreover, Carter and McCarthy (2006, p423) mention that "The -ing form also occurs in non-finite clauses". For example, Molly once said "Like you might say "fingers crossed" means that you pray for the situation" when it should be "meaning that". On the other hand, Molly tends to confuse the verb and noun forms of a word. For example, she used to say "sale something" instead of "sell something".

- Modal verbs

Molly is sometimes unable to choose the correct modal verb. For example, she said "I will be stupid but I will never lose my sense of humour" where she could have used "may", and "They really need to pay me something" producing an entirely different meaning from what she was attempting to say, "They really should pay me something". Also, examples such as "I would have finished all those things and I can start a job" where it should be "could have started a job". However, it is easier for Molly to grasp the function of modal verbs because they are frequently used in every-day life and the number of modal verbs is limited. Also, modal verbs are used within certain contexts and the general rules for their use are very similar.

\section{Subsection discoveries}

Carter (1998, p5) regards grammatical words as "functional words" or "empty words", such as pronoun (you, they, me), prepositions (in, on, by) and conjunctions (and, but). On the other hand, he indicates that lexical words are known as "full words" or "content words", such as noun (man, rabbit), adjectives (beautiful, handsome), verbs (sleep, eat) and adverbs (quickly, luckily). From Molly's English immersion experience, it seems that she could obtain more content words, such as content noun, adjective, adverb and collocations, through "subconscious mechanism" (Scheffler, 2015). For instance, she has been trying to memorize these kinds of lexis from vocabulary books, with Max and Pauline helping with explanations but she found this process both inefficient and ineffectual, only rarely would a newly-acquired term or phrase slip out in conversation whereas, she could quickly learn new vocabulary from, for example, shopping with Pauline. She can receive abundant content information from her conversation with Pauline and with other people, and even from item names and descriptions in shops. In this respect, she tends to separate the information she gains through reading from that obtained from real life. As to functional words, however, Molly achieved better acquisition from "conscious study" (Scheffler, 2015) of such groups as determiners, prepositions, pronouns and auxiliary verbs. As long as she understands the rules, she could make use of them in her own spoken English and she could also identify them when listening to a native speaker.

Jones (2018) conducted a research to examine the effectiveness of immersion versus engagements in the classrooms and she found that interactions with native speakers in real living situations can enhance students' retention of English. There is evidence from the two groups of data that Molly's capacity of content words and expressions has increased from her home-stay experience. For example, she has gained new words for different dishes, such as "toad in the hole" and "Welsh rarebit"; and she learnt new words, such as "curriculum" and "commission". Also she has discovered expressions, such as "out of the blue", "draw the line", "my cup of tea". She acquired this kind of knowledge from her interaction with Max and Pauline, not from the books. However, her learning and application of functional words is taking time and there seems to be little, if any, obvious improvement. These functional words in lexis have a strong connection with grammar and even, with explicit and systematic instruction, Molly still makes mistakes from time to time.

\section{Grammatical difficulties in communication}

Data presentation and analysis

Among all the grammatical difficulties Molly has encountered, her inaccuracy of tense seemed far to exceed the others. In order to draw a clearer line between grammar and lexis, the grammar difficulties in this paper are focused on the 5 categories shown in Chart 4 below:

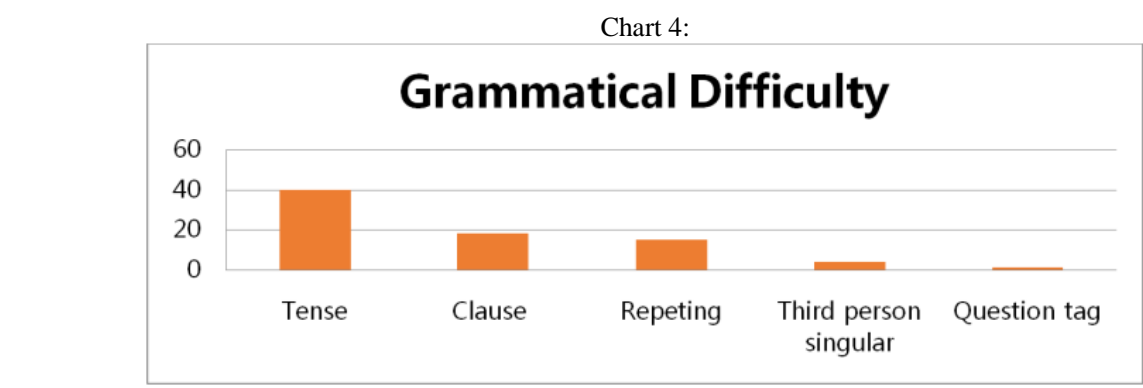

*Note: The numbers refer to the amount of grammatical mistakes collected from Molly's recorded conversation.

- Tense

For example, Molly said "I wear, I wore earplugs, and I fall fell asleep." "Have you ever swim, swam in the sea?" "I 
didn't worked, I have never worked in that training school" She was correcting herself while she was speaking. It seemed that her brain was a little slower than her mouth when it came to dealing with tense. From the data, past simple was the biggest challenge for Molly. For example, she said "...this morning as well when I woke up it is so quiet." She knew that she should use the past simple "woke up" instead of "wake up" but she ignored the "is" where she should have said "was". From an academic view, Molly is aware of the rule of past simple but she could not help making such mistakes. As to present perfect, Molly sometimes confused it with simple present or simple past, especially with the simple present. For example, she said "I can't believe that you just finish that big piece of cheese." where she should have said "you've just finished". From the data, it seems Molly is more capable when using the future tense and very rarely confused it with other tenses.

- Using declarative as a question

With respect to clause, Molly has a habit of asking a question using a declarative statement with a rising tone in the end. For example, she asked Pauline "So Adrienne is with them in Greece now?" "Why they changed now?" She could have said "Is Adrienne with them in Greece now?" and "Why did they change now?" Carter and McCarthy (2006) discovered affirmative and negative declarative clauses may also occasionally function as questions or requests. Although this phenomenon is acceptable in communication, it may be even more popular among L2 learners than for native speakers.

- Missing a subject/object

On the other hand, Molly sometimes would miss a subject or an object in her spoken clause. For example, she said "They have a very cozy home, not very big but is very comfortable." where she should have said "but it is very comfortable". Also, she said "Actually they sent to me the afternoon before I arrived home." where it should be "they sent it to me ..." In Carter's (1998) opinion that ellipsis is actually more appropriate than full forms in certain situations where full forms may be irritating and time-consuming. However, in Molly's case, it seems it is not a choice of ellipsis in her spoken language but a mistake she needs to pay attention to.

- Repeating

Carter and McCarthy (2006) reveal that speakers may repeat or recast what they said under the pressure of real time communication and this cannot be regarded as sloppy. Repeating is also common in Molly's utterance. For example, She said "...she says people working there they are very friendly to her." "...but one of my cousins, she got to school at the age of four." "You know, some people, they just don't have good manners" In this case, Molly is repeating the subject in her speaking. Although it does not hold up the conversation, but it seems an interesting phenomenon that she does not repeat other parts of the sentence, only the subject.

- Conjunction

Carter and McCarthy (2006) pointed out that real-time communication do not give speakers time to construct well-planned patterns of main and subordinate clauses, and sequences of clauses linked by coordinating conjunctions (and, but, or) or by simple subordinating conjunctions such as because and so are more commonly used. Molly is aware of this feature, however, the problem is that she tends to repeat the same conjunctions too many times making her speech repetitive and uninteresting. For example, she said "And then we stayed there for one week, I mean in St. Joseph College for one week. And then we went to Washington for a week and then New York for a week. And then we came back to Indiana, and then we went to Chicago."

- Third person singular

As to the form of third person singular, Molly often forgot about the correct $-\mathrm{s}$ form. For example, she said "sometimes she still tell me that she miss him" where she should have said "tells" and "misses". The reason for Molly making such mistakes is probably that there is no such form alteration in the Chinese language. Molly's L1 may have had another negative transfer on her English outcome in this respect.

- Question tag

In addition, Molly made mistakes with question tag. Tags are "short clauses added on to the main clauses either to create questions or to reinforce statements, directives and exclamations" Carter and McCarthy (2006, p532). Molly said "But you have, you know, the minimum wage, isn't it?" The tag "isn't it" here is not coherent with the main clause grammatically. The correct tag could be “don't you?" or "haven't you?" It seems Molly could add the tag "isn't it" on to any clause no matter whether it is positive or negative, whether it relates to a person or an article, or contains an auxiliary verb, an auxiliary be, or a modal verb. For example, she could say "Lily does like the dress, isn't it?" "We can go out this afternoon, isn't it?" It works for Molly and she normally receives effective responses from the listener when she says "isn't it?" and that is probably why she doesn't consider its incorrectness.

\section{Subsection discovery}

Hedge (2000, p146) points out the importance of noticing in learning grammar, and he states that "...learners pick out specific features of the language and pay attention to them". Although Molly made mistakes in spontaneous speech, she could explain most of the grammar rules when she started to analyze her own errors and she found the process of noticing very helpful. Therefore, Molly prefers explicit teaching of grammar and she considers that there is little opportunity for her to pick up grammar "naturally" even from sufficient exposure to lexical items or chunks. She spent ten years learning English in school and university in China which she believes has laid a solid foundation for her English language competence. She is confident that this grounding will benefit her no matter where her career may lead. 
Scheffler and Cinciata (2011) signify that knowing explicit grammar rules can help learners to notice the structures that exemplify rules in the input, as well as helping them to obtain more comprehensive input. This is especially so in Molly's case. After she has analyzed the first group of data, she started to notice more of the grammatical structures in the input she received every day from the linguistic environment, especially from her conversations with native speakers. For example, she began to notice modality more often in conversations, and it not only helped her to receive more comprehensible input from native speakers but also to use it herself more practically. However, Molly holds a view that, even if she has understood the underlying grammar rules, it will still take a lot of practice in real situations before she will be able to make use of them accurately in spontaneous speech.

\section{Pronunciation difficulties in communication}

\section{Data presentation and analysis}

Although Molly is comfortable with her English having a Chinese accent, English vowels have posed her the biggest challenge. See details below:

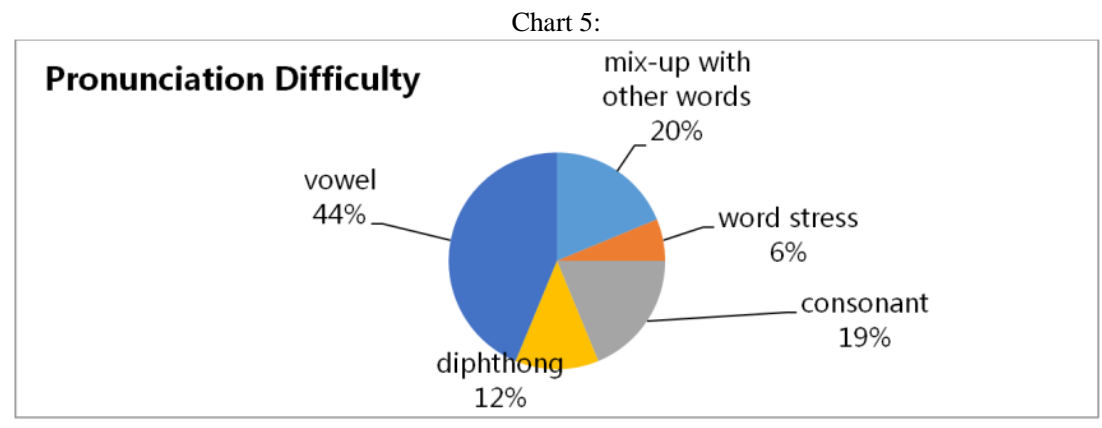

- Mix-up with other words

Sometimes Molly tends to mix up the pronunciation among different words. For example, when she observed to a friend that they wore the same size of clothes, she said "...we are kindly (kind of) in the same size." where she pronounced the word "kindly" instead of "kind of". And another time when she wanted to say "need", it sounded like "near" where there is no " $\mathrm{d}$ " sound at the end. Molly is confident that it was not because she did not know these two words but really due to accidental mispronunciation. It seems that if she spoke quickly, there was more chance of her making such mistakes. She also has a slight difficulty with word stress. For example, she sometimes pronounced "Pauline" with a stress on the second syllable rather than the first.

- Vowel

With some vowel sounds, Molly experiences difficulty in selecting the appropriate long or short vowels. For example, from listening to the recording, she often mispronounces "live - /liv/" as "leave - /li:v/" which could convey a completely different meaning leading to unfortunate or embarrassing misunderstanding. The long vowel phonemes are those with a lengthening symbol /:/. As Kelly (2000: 31) explains for pronouncing /i:/, the lips should be spread and the tongue should be tense while for the short vowel /i/, lips are spread loosely and the tongue should be relaxed. However, Molly invariably pronounces both /i:/ and /i/ with spread lips. Also, she had some problems with diphthongs, which Kelly (2000: 34) defines as "a combination of vowel sounds" The most difficult one for Molly is the /ei/ sound because she often mixed it with the vowel /e/, such as the word "nail".

- Consonant

Molly is sometimes confused by the pronunciation of /1/ and /n/. For example, when she wanted to say "I knocked on the door three times", she actually said "I locked on the door three times" which had exactly the opposite meaning. Kelly (2000) gave a learner-friendly exercise for these two consonants: Put the front of your tongue against the bump behind the teeth. Use the voice, and let the air pass out of your mouth for $/ 1 /$ and let the air escape through your nose for /n/. There are also /1/ and /n/ sounds in Chinese and, as Molly is capable of pronouncing them correctly, there should be a positive influence on her L2 pronunciation of these two sounds. Also, there was one time when Molly mispronounced the voiceless and voiced sound $/ \mathrm{p} / \& / \mathrm{b} /$ and $/ \mathrm{k} / \& / \mathrm{g} /$ in the word "magpie" but she corrected herself immediately afterwards.

\section{Subsection discovery}

Cook (2008) summarizes that the sound of language is a complex system which cannot be learnt at a time. Learners have they own "interlanguage phonologies" which are unique rules of their own. In Molly's situation, even though she had some difficulties in her own pronunciation, it should not hinder her from understanding native speaker's pronunciation as evidenced from how their conversations were continued. Walker (2010) also indicates that learners should receptively cope with the pronunciation features that they themselves could not produce. Gilakjani (2017) suggests that teachers should guide learners towards understandable pronunciation but not exactly native-like pronunciation. Molly could make efforts to practice the pronunciation repeatedly so as to improve her native-like linguistic competence, but it should not affect her communication in general.

From the outset of Molly's acquaintance with Max and Pauline, Molly requested them to draw her attention to any 
mispronunciation she might make and she valued all the corrective feedbacks she received. Corrective feedback (CF) refers to teacher and peer responses to learners' incorrect L2 productions ( $\mathrm{Li}, 2014)$. Max and Pauline both agreed that Molly's pronunciation had improved during the recording gap, so that Molly herself is convinced that her pronunciation can be developed with repeated physical practice. Also, as mentioned before, Molly can spot for herself most of the pronunciation mistakes she might make and she could pay immediate attention to them. Last but not least, Molly discovered that her satisfaction with her aptitude in English has been the main reason for her interest and confidence in learning English.

\section{Second language acquisition in communication}

Data presentation and analysis

- Linguistic environment

From the transcripts, it is noticeable that when Molly was relaxed and enjoying herself in conversation, her speaking performance seemed better, whereas sometimes the purpose of recording did put her under some pressure which impacted adversely on the accuracy of her spoken English. However, it has been more than 6 months since Molly moved to stay with Max and Pauline and they have maintained a friendly relationship ever since. Therefore, Molly should be able to present authentic spoken performances within such a linguistic environment. Whilst in the UK, Molly had met many native speakers from different walks of life, such as her foreign teachers and classmates, friends from the church, Max and Pauline's family and friends, and strangers in shops and restaurants. She speaks English frequently, almost as much as she spoke Chinese back in China.

When Pauline and Molly were talking about Primark, Pauline said: "Lots of people won't go there because of the ethics of it." and Molly replied "What do you mean the ethics of it?" Obviously, Molly knew the meaning of the word "ethics" but she did not know what Pauline referred to and she was negotiating for meaning. Ortega (2009) points out that negotiation for meaning carry potentials for learning and attract attention to the language code. This displays positive evidence that Molly was taking the language advantage from the native speaker and Pauline's explanation would assist Molly to accumulate vocabulary with different connotation. By contrast, when Molly wanted to tell Pauline that there were a lot of seagulls on her roof and it was very noisy, she said "I have this window on the roof, and those seagulls, very noisy." Apparently Pauline understood Molly because she knew the situation. However, Molly was not aware that she was using an incomplete and ungrammatical sentence. Although the communication was effective in conveying the information, Molly's descriptions could have been better.

The transcripts also show that Molly tends to use "gonna" a lot and she very often applies the word "like" in her spoken language. For example she said "I think her mother-in-law is gonna take care of her." and "They prepared lots of things for us; like we went to like local farms every day, like different farms." Some native speakers use "gonna" and "like" very often when speaking and it gave Molly the impression that it would make her sound more native-like if she introduce this usage into her every-day speaking and, at the same time perhaps help her to engage more easily in conversation. Cater (2007, p43) mentions that certain chunks, such as "sort of" and "you know" mark native speakers, and goes on to suggest those who desire native-like proficiency should learn to use them. However, it may be regarded as sloppy English and an L2 learner is often uncertain under which circumstances it would be appropriate to use such terms, acquired from badly-spoken input.

- Individual differences

As mentioned above, this research focuses on one advanced learner, therefore, the individual differences of this learner will probably determine the emphasis of the research in many respects. Ortega (2009) discovers that personality traits will influence the success of an L2 study. Some individuals experience a sense of apprehension, tension, and even fear when they think of foreign languages, which Ortega (2009) regards as "foreign language anxiety." Molly has an interest in English language debating and public speaking so that she is confident of her own linguistic and communicative competence in English. In her conversations with other L2 learners like herself, she tries to take the initiative to break the ice and open a dialogue, always being keen to develop and extend a conversation. However, it seems that she is reserved when talking with a native-speaker, demonstrating that foreign language anxiety influences Molly's intensions and spoken performance.

In one of the conversations from the transcripts, Molly spelt the word "salt" as "sault" saying "I can't make mistakes like this, being an advanced English learner." From a psychological point of view, Molly felt ashamed of her mistake. People often make spelling mistakes, even some native English speakers. However, a minor mistake can put more pressure on L2 learners who make great effort to improve their language competence whereas native speakers may regard minor errors as relatively unimportant. Also, L2 learners' different attitudes towards mistakes will have varying impact on their learning; some may be encouraged to improve while others might be disheartened. Molly recalls an experience during her undergraduate years when she was a bilingual broadcaster. Initially, she was wary of speaking Chinese in the office as everyone else spoke standard mandarin. It was the fear of making mistakes and people's judgment that made Molly afraid of speaking even her mother tongue at that time.

- L1 influences

Molly is from China, and Chinese is her mother tongue. Universally, mother tongue would influence the processes and outcome of L2 learning. Ortega (2009) explains that knowledge of the L1 interacts with L2 development by accelerating or delaying the learning process but it will not override it. Ellis (1997) considers that L1 influence might 
result in negative transfer causing errors in the learner's language or, in some cases it might be a positive transfer helping to facilitate L2 acquisition. For example, Molly found L1 influence in her difficulty with numbers. When somebody mentions a sum of money, it always takes a long time for her to figure out how much it is. For example, $£ 10,000$, she would first convert into RMB 100,000 and then use the Chinese unit Wan, which is 1,0000, to finally know its value as 10 Wan, i.e. 10.0000. In real conversation, this cognitive process would certainly slow down the communication.

Another example of negative L1 influence is that Molly was sometimes confused with the plural and singular forms of a noun. This feature of the English language seems so demanding and complicated for a Chinese L2 learner, because it is not just a matter of adding an "s" at the end of a noun, but different nouns may have different plural forms. Also, there are non-count nouns which can be even more confusing. On the other hand, Molly tends to ask "Do you understand what I mean?" in the middle of her descriptions. It is not because she intends to check the interlocutor's comprehensive ability, but to ensure she is making herself clear and to find out whether she could have illustrated it better. Subconsciously, she reminds herself that she is speaking a second language and her interlocutor might find her way of saying things strange so that she needs to double-check.

- Culture differences

Tseng (2002) emphasized that competence in language requires the ability of using the language accurately and also knowing the culture that underlies the language. There was a time when Max wanted to tease Molly about British food. Max told Molly that he would cook her "toad in the hole" for supper. Molly was shocked "How can people eat a toad?" but she was afraid to decline the offer and did not know how to develop the conversation. However, Molly's reaction perfectly suited Max's intention and it turned out to be very entertaining. When Molly was explaining to Pauline the different levels of university in China, she referred to them as A-level University, B-level University, etc. Pauline could not understand her because she was thinking in terms of the U.K. secondary school A-level exams whereas Molly referring to the ranking of Chinese universities.

Here is another example relates to the cultural differences between Molly and the native speakers which have influenced the communication. For example, when Molly was asked whether she would like more potatoes, she just shook her head and said "hmm..." Max later pointed out that most British people would say - or certainly would be expected to say - "Thank you" in response to a service rendered or "No, thank you" to a service declined. In British culture a shake of the head is not an acceptable or polite response. Similarly, the use of "please" within a request for a service is almost essential. Molly also noticed a phenomenon that when British people mention someone, they will often give the name of the person straight away whereas Chinese people are more reticent in disclosing somebody's name to a stranger. Also, Molly found it interesting that British people kiss each other on meeting and parting but they do not normally like to walk arm in arm or hand in hand.

- Cognition

Irrespective to a learner's language level, it is more likely that cognition is more dependent upon general ability. Williams (2012, p427) defines the term "working memory (WM)" as a temporary storage system. He explains that WM is not just a short-term storage of information, but also a processing of that information so as to achieve a certain result. Molly always has problems remembering English names, especially place names. For example, there is a pub in town called Richard John Blackler and Molly used to pass it every day on her way home. But she always referred to it as "that pub opposite to Boots". She tried to remember the name but her working memory refused to retain it. It is the same with Indianapolis, she was never able to pronounce it correctly and she had to say "the capital of Indiana". Even familiar names, such as "Welsh rarebit", she found difficult to remember, whenever she heard a new name in a conversation, her brain immediately ignored the information, even with people's names, such as Shane, Gerald, and Annette. If she needs to explain something relating to a particular name she had to come up with a lot of peripheral information to identify the person or object which can obstruct the natural flow of a conversation. Perhaps it is because her brain finds it easier just to say "that building", "that person" or even simply to point to the things she wants to say.

\section{Subsection discovery}

Molly is sometimes afraid to take risks in her speaking and she tends to apply guessing, paraphrasing and avoidance quite frequently under such pressure. As a consequence, there may be only superficial understanding deriving from her conversations with native speakers and this must have a negative effect in her language learning. Molly's fear of talking to a native child and making mistakes in front of the others is almost certainly due to her foreign language anxiety. Zafar \& Meenakshi (2012, p644) decribes anxiety as "the feeling of uneasiness", "frustration", "self-doubt", "apprehension", or "worry". And this can be affected by various factors such as the number of people present, the topic, and the circumstances. But Zafar \& Meenakshi’s (2012) also admit that not all anxiety generates negative influence as a certain amount of tension could sometimes facilitate learning. It is revealed from Molly's spoken performance, her L1 influenced her application of plural and singular forms of a noun, third person singular, word order, numbers, different verb forms etc. As to the cognition difficulty experienced by Molly, Zafar \& Meenakshi (2012, p644) suggest a few cognitive strategies, such as "visualizing information for memory storage", "keeping a sound or sound sequence in the mind", "relating new information to other concepts in memory" and etc. 


\section{CONCLUSION}

\section{Summary to research questions Linguistic difficulties}

A total of 205 mistakes are recorded in Appendices 1 to 10, lexis accounting for approximately 54\% of the errors, grammar 38\% and pronunciation 8\%. Molly's difficulties with lexis have been divided into two parts: a lack of sufficient content words or expressions and also the struggle to use them within appropriate context and a weakness in making correct use of functional words. With respect to her difficulty with grammar, her inaccuracy with tense, especially past simple, is most prevalent. As to pronunciation, her biggest problem is her frequent mispronunciation of long and short vowels.

As revealed by the data, Molly sometimes corrects herself while she is speaking. From her previous study, she may have possessed a satisfactory capacity of lexis and grammar but she has difficulty in relating them to appropriate context for real use. With regard to her confusion of functional words and grammatical rules, L1 influence may be one of the main reasons, as well as perhaps an element of laziness obstructing the achievement of accuracy in spoken language. On the other hand, she needs to notice her weaknesses and should device strategies to correct them. Also, her limited usage of descriptive expressions and words, it is not only a matter of accumulating rich vocabulary, but also a determination to overcome the fear of taking risks in using them. Finally, her mispronunciation of long and short vowels may be due to her incorrect way of spreading the lips.

\section{Psychological difficulties}

In Molly's communication with native speakers, she relies on the habit of guessing and avoidance, and she expects her interlocutor to understand her even if she fails to convey her message fully, sometimes by ending with "Do you understand?" Her self-esteem urges her to make improvements in her linguistic competence but she feels a lack of confidence when speaking in front of a native speaker. Molly is aware that, subconsciously, she sometimes blocks the receipt of complicated target-language input and she is fearful of expressing uncertain information. As a consequence, she may be creating blind-spots which she realizes need to be overcome.

In Molly's case, foreign language anxiety has posed a major challenge to her self-confidence in second language acquisition. Her caution when speaking a second language has inhibited the spontaneity of her spoken discourse with native speakers. In this respect, Molly's needs and wants for reaching a high-level of spoken proficiency may overcome her anxiety and motivate her to offload this burden. In addition, cultural differences and L1 influence have some conscious and subconscious impact on her performance. Nonetheless, personality may play a more important role than linguistic competence in real life communication.

\section{Recommended study strategies}

During the gap between recording the two groups of data, Molly paid specific attention to mistakes discovered from the first group of data. It reveals that her usage of various content words and expressions have been enlarged since she started to collect them from the input in everyday life, and her pronunciation has been improved due to corrective feedback and repeated physical practice. However, there is no obvious progress with her grammar and usage of functional words.

Molly found that she hardly increased her vocabulary by attempting to memorize lists of words but was subconsciously acquire new words and expressions from everyday life. As Tomlinson $(2013$, p12) summarized that "a rich and meaningful exposure to language in use" would facilitate SLA. Secondly, Molly established a good relationship with Max and Pauline and she is appreciative of such a learning opportunity in which the emotional aspect has played an important role. This phenomenon fall into the category of "Affective and cognitive engagement" as Tomlinson (2013, p12) would mention. Tomlinson (2013) also suggest to make use of the mental resources which are typically used in communication in the L1. The resources he refers to are visualization and inner voice. Molly attempts to organize her ideas using inner voice in English, at the same time visualizing the image. She has discovered that it is a good way of stretching her skills without interference from outside pressure and it is helping her to overcome her foreign language anxiety. Finally, Tomlinson also emphasizes the importance of noticing. As mentioned, Molly has benefitted from her notice of mistakes she made, as recorded in the first group of data, and it is apparent that she had made progress subsequently.

\section{Findings}

This research reveals that grammar does not usually inhibit Molly in communication with native speakers whereas the lack of appropriate vocabulary always slows down her response. As to the difficulties with lexis, it seems to be possible to collect content words and expressions without formal instructions if there is sufficient immersion in the target language environment whereas the acquisition of functional words and the use of accurate grammar are more likely to be achieved from systematical instructions. The subsequent assimilation of these consciously-learnt rules and concepts for successful application in everyday use is almost always a lengthy process. With regards to pronunciation, it appears that certain sounds might present a challenge for some advanced learners if they have already picked up a habit of their own. However, pronunciation can be improved with constant physical practice and corrective feedback.

From a psychological point of view, foreign language anxiety seems to be a major problem in the communication between Chinese advanced learners and native speakers. In addition, cultural differences and L1 influence play an important role in their communication and interaction. 
Last but not least, the study strategies derived from the research show that receiving continuous language exposure is the best way for advanced learners to improve their linguistic and pragmatic competence.

\section{Limitations}

First of all, Molly is playing the roles both of participant and a researcher. Consequently, there is an underlying risk of influencing the objectivities of the research. The data include not only the linguistic difficulties in Molly's speaking but also the psychological problems that she encountered in facing those difficulties. The psychological data is certainly subjective but also unique in displaying an immediate response and reaction of a Chinese advanced learner. It may contribute to future study if another participant is involved for documenting Molly's response rather than her doing it herself, although it might reduce the authenticity of the actual feeling of the participant. Furthermore, this research could have involved a few more Chinese advanced learners as participants but that would have greatly extended the scope of the research, which could be further explored.

\section{ACKNOWLEDGEMENTS}

First and foremost, I want to thank Max Pugh and Pauline Pugh who have made fundamental contributions to the research. This research would have been impossible to carry out without their participation and support. They have been making significant efforts during the whole research process and have showed great kindness and patience. Also, I would like to give my sincere thanks to Hitomi Masuhara and Stephen Pihlaja for their vital guidance and instructions. Last, but far from the least, I would like to thank Margaret Hughes and Sandra James who have provided understanding and support while I was concentrating on the writing.

\section{REFERENCES}

[1] Bygate, M. (1987). Speaking. Oxford: Oxford University Press.

[2] Cohen, L., Manion, L. \& Morrison, K. (2007). Research Methods in Education. London: Routledge.

[3] Carter, R. (1998). Vocabulary: Applied Linguistic Perspectives. London: Routledge.

[4] Carter, R. (1998). 'Orders of reality: CANCODE, communication, and cultural'. English Language Teachers Journal, Vol. 52/I, p43-45.

[5] Carter, R. \& McCarthy, M. (2006). Cambridge Grammar of English: A Comprehensive Guide: Spoken and Written English Grammar and Usage. Cambridge: Cambridge University Press.

[6] Carter, R. (2007). 'What is advanced level vocabulary? The case of chunks and clusters' In Davidson, P., Coombe, C., Lloyd, D. \& Palfreyman, D. (eds.). Teaching and Learning Vocabulary in another Language. Dubai: TESOL Arabia.

[7] Cook, V. (2008). Second Language Learning and Language Teaching. London: Arnold.

[8] Ellis, R. (1997). Second Language Acquisition. Oxford: Oxford University Press.

[9] Gilakjani, A. (2017). "English Pronunciation Instruction: Views and Recommendations". Journal of Language Teaching and Research, Vol. 8/6, p1249-1255.

[10] Gairns, R. \& Redman, S. (1986). Working With Words: A Guide to Teaching and Learning Vocabulary. Cambridge: Cambridge University Press.

[11] Harley, A. (2010). Talking the Talk: Language, Psychology and Science. Hove: Psychology Press.

[12] Hedge, T. (2000). Teaching and Learning in the Language Classroom. Oxford: Oxford University Press.

[13] Jones, A. (2018). 'Immersion versus Engagement Strategies: Examining the Effects on Conversational Competence amongst Korean Students in an Intensive English Program'. Journal of Language Teaching and Research, Vol. 9/4, p665-674.

[14] Jenkins, J. (2009). World Englishes: A Resource Book for Students. London: Routledge.

[15] Kelly, G. (2000). How to Teach Pronunciation. Harlow: Longman.

[16] Kang, O. \& Ghanem, R. (2016). 'Learners' Self-perception of Target Language Study in Overseas Immersion'. Journal of Language Teaching and Research, Vol. 7/5, p819-828.

[17] Kim, Y., Hutchison, L. A., \& Winsler, A. (2015). 'Bilingual education in the United States: an historical overview and examination of two-way immersion.' Educational Review, Vol. 67/2, p236-252.

[18] Li, S. (2014). 'Oral corrective feedback' English Language Teachers Journal, Vol. 68/2, p196-198.

[19] Maley, A. (2009). Advanced Learners. Oxford: Oxford University Press.

[20] Ortega, L. (2009). Second Language Acquisition. London: Hodder Education.

[21] Sykes, A. (2015). 'The Good Language Learner Revisited: A Case Study'. Journal of Language Teaching and Research Vol. 6/4, p713-720.

[22] Scheffler, P. (2015). 'Lexical priming and explicit grammar in foreign language instruction'. English Language Teachers Journal, Vol. 69/1, p93-96.

[23] Scheffler, P. \& Cinciała, M. (2011). 'Explicit grammar rules and L2 acquisition'. English Language Teachers Journal, Vol. 65/1, p13-23.

[24] Tomlinson, B. (2013). Applied Linguistics and Materials Development. London/New York: Bloomsbury Academic.

[25] Tseng, Y. (2002). 'A lesson in culture'. English Language Teachers Journal, Vol. 56/1, p11-21.

[26] Williams, J. (2012). Working memory and SLA. In Gass, S. \& Mackey, A. (eds.), The Routledge Handbook of Second Language Acquisition. (pp: 427-441). New York: Routledge.

[27] Walker, R. (2010). Teaching Pronunciation of English as a Lingua Franca. Oxford: Oxford University Press.

[28] Zafar, S. \& Meenakshi, K. (2012). 'Individual learner differences and second language acquisition: a review'. Journal of Language Teaching and Research. Vol. 3/4, p639-646. 


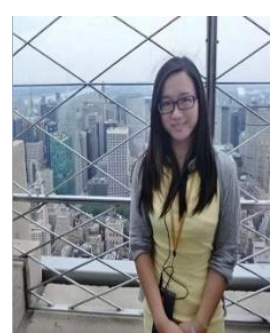

Xiaoling Jin was born in Hubei, China in 1989. She received her Master's degree in Teaching English to Speakers of Other Language in 2015 and she is currently seeking for potential $\mathrm{PhD}$ opportunities.

Ms. Jin is currently a teaching staff in the program of English Language and Literature Studies in Beijing Normal University Hong Kong Baptist University United International College (UIC), Zhuhai, China. Her research interests include Chinese English, sociolinguistics, e-Learning education and TESOL. 